\title{
Efeito do pH na Calcificação In vitro de Pele Porcina
}

\author{
Thelma M. Batista, Virginia C. A. Martins, Carlos A. S. Bento, Ana M. G. Plepis \\ Instituto de Química de São Carlo, USP
}

\begin{abstract}
Resumo: A engenharia de tecidos tem sido utilizada como alternativa na reconstrução de tecidos duros e moles. Este estudo teve como objetivo a calcificação "in vitro" de pele porcina visando à obtenção de um material para regeneração de tecido duro. As matrizes de pele porcina foram calcificadas em cela dupla termostatizada a $37^{\circ} \mathrm{C} \mathrm{em} \mathrm{pH} \mathrm{7,4} \mathrm{e} \mathrm{pH} \mathrm{9,0} \mathrm{e} \mathrm{caracteri-}$ zadas por microscopia eletrônica de varredura (MEV), termogravimetria (TGA), espectroscopia no infravermelho (FTIR), calorimetria exploratória diferencial (DSC) e difração de raios X. Os resultados obtidos por DSC mostraram que as amostras calcificadas têm um pequeno aumento nos valores de temperatura de desnaturação em relação à amostra não calcificada, enquanto as curvas termogravimétricas mostraram uma porcentagem maior de material inorgânico para o pH 7,4 em comparação com as amostras obtidas em pH 9,0. A formação de sais de fosfato de cálcio nas fibras de colágeno foi confirmada por difração de raios X (DRX), espectroscopia no infravermelho (FTIR) e microscopia eletrônica de varredura (MEV).
\end{abstract}

Palavras-chave: Colágeno, calcificação, hidroxiapatita.

\section{In Vitro Calcification of Porcine Skin: Influence of pH}

Abstract: Tissue engineering has been used as an alternative in the reconstruction of hard and soft tissues. The objective of this work was to study the in vitro calcification of porcine skin aiming at obtaining a material to be used for regeneration of hard tissue. Pig skin was calcified at $37^{\circ} \mathrm{C}, \mathrm{pH} 7.4$ and pH 9.0 and characterized by scanning electron microscopy (SEM), thermogravimetric analysis (TGA), infrared spectroscopy (FTIR), differential scanning calorimetry (DSC) and X ray diffraction (XRD). The results obtained by DSC showed that calcified samples had a small increase in the values of denaturation temperature when compared with uncalcified samples. Thermogravimetric curves showed higher quantity of inorganic material for the $\mathrm{pH} 7.4$ matrix when compared to samples obtained in $\mathrm{pH}$ 9.0. The formation of calcium phosphate salts on collagen fibers was seen by SEM, which was also confirmed by X ray diffratogram and FTIR.

Keywords: Collagen, calcification, hydroxyapatite.

\section{Introdução}

A estratégia biomimética utilizada no desenvolvimento de novos materiais para reconstrução de tecido ósseo inspira-se nos processos bioquímicos e biofísicos que ocorrem na formação dos tecidos mineralizados. A matriz extracelular na qual os cristais de sais de cálcio se depositam durante a formação de tecido ósseo é principalmente colágeno, que constitui cerca de 95\% da matéria orgânica do osso. Sendo assim, matrizes que contenham colágeno e hidroxiapatita (HA) são materiais promissores para serem usados como base para um substituto biodegradável do osso, dentro da engenharia de tecido ${ }^{[1-3]}$. A desvitalização de matrizes homólogas ou heterólogas é uma alternativa viável para a produção dessas matrizes extracelulares (MECs) ${ }^{[4]}$, servindo como suporte tridimensional para crescimento do novo tecido. Várias MECs de colágeno tem sido estudadas ${ }^{[5]}$, tais como esponjas de colágeno com deposição de fosfato de cálcio que tem demonstrado grande potencial para aplicação em reconstrução óssea através dos resultados obtidos em culturas de condrócitos ${ }^{[6]}$. Filmes de colágeno recober- tos com hidroxiapatita tem demonstrado migração de células de tecido ósseo para o interior da matriz, sugerindo que o material é bioativo ${ }^{[7]}$.

As MECs de colágeno ainda têm a vantagem de serem modificadas quimicamente alterando suas propriedades superficiais, dentre essas modificações a hidrólise seletiva dos grupos carboxamidas dos resíduos de aminoácidos asparagina (Asn) e glutamina (Gln) do tropocolágeno ${ }^{[8]}$ produz uma matriz carregada negativamente a $\mathrm{pH} 7,4$, obtendo-se uma matriz de colágeno polianiônico. Compósitos dessas matrizes com hidroxiapatita não-estequiométrica mostraram uma baixa irritabilidade tecidual, permitindo a evolução reparativa do tecido ósseo ${ }^{[9]}$. A avaliação biológica em ratos mostrou que após sessenta dias de implante o compósito encontrava-se incorporado ao processo de ossificação com as cavidades ósseas quase que totalmente preenchidas por tecido ósseo.

Neste trabalho utilizou-se a pele porcina que contém como constituinte principal o colágeno tipo I e ainda por ser uma fonte bastante comum na obtenção de materiais de heterólogos, devido a sua similaridade com a pele humana ${ }^{[10]}$.

Autor para correspondência: Ana M. G. Plepis, DQFM, Instituto de Química de São Carlos, USP, Avenida do Trabalhador Saocarlense 400, Caixa Postal 780, CEP: 13560-970, São Carlos, SP, Brasil.E-mail: amplepis@iqsc.usp.br 
Esta matriz após hidrólise seletiva dos grupos Asn e Gln, foi calcificada em pH 9,0 e pH 7,4, com o objetivo de nuclear sais de fosfato de cálcio nas fibras de colágeno, para ser utilizada na substituição e regeneração de tecidos duros.

\section{Experimental}

\section{Preparação da matriz}

A pele porcina foi tratada a $25^{\circ} \mathrm{C}$, com uma solução contendo sais de $\mathrm{KOH}, \mathrm{NaOH}, \mathrm{Na}_{2} \mathrm{SO}_{4}, \mathrm{KCl}, \mathrm{NaCl}$ e $\mathrm{Ca}(\mathrm{OH})_{2}$ por um período de $96 \mathrm{~h}$, sendo em seguida estabilizada com cloretos e sulfatos de $\mathrm{K}^{+}, \mathrm{Na}^{+}$e $\mathrm{Ca}^{2+}$ por $6 \mathrm{~h}$ e neutralizada com solução de ácido bórico 3\% Após a neutralização, a pele porcina foi lavada com solução de EDTA $0,3 \%$ para remoção de cálcio $^{[8]}$. Após remoção completa dos sais, a matriz foi equilibrada em ácido fosfórico $0,001 \mathrm{molL}^{-1}$ por um período de 48 h. Em seguida foi lavada com água deionizada e cortada em pedaços de 2,0 cm de diâmetro (matriz A).

\section{Estudo de calcificação}

O estudo de calcificação foi realizado em cela dupla (Figura 1) termostatizada a $37{ }^{\circ} \mathrm{C}$ e sob agitação, com soluções de $\mathrm{CaCl}_{2}$ 0,1 mol.L $\mathrm{L}^{-1}$ e $\mathrm{NaH}_{2} \mathrm{PO}_{4}$ 0,06 mol.L $\mathrm{L}^{-1}$ em pH 7,4 e 9,0 por períodos de $24 \mathrm{~h}$ (matrizes B e D) e $72 \mathrm{~h}$ (matrizes C e E), respectivamente. Após a calcificação, a matriz foi lavada com água deionizada, congelada e liofilizada.

\section{Caracterização do material}

s - ICROSCOPIA EIEIR NCA DE VARADUR - \% ! s FOCmicrografias foram obtidas da pele porcina calcificada e sem calcificação em um equipamento LEO 440, operando com feixe de elétrons de $20 \mathrm{keV}$, com amostras previamente cobertas com uma liga ouro-paládio;

s \$ IHRA/AC DE RAOE 8 / DIRATOCRAMA DE Uvi AMOSTR da matriz calcificada de aproximadamente $1 \mathrm{~cm}^{2}$ foi obtido em um difratômetro Universal e raios X Carl

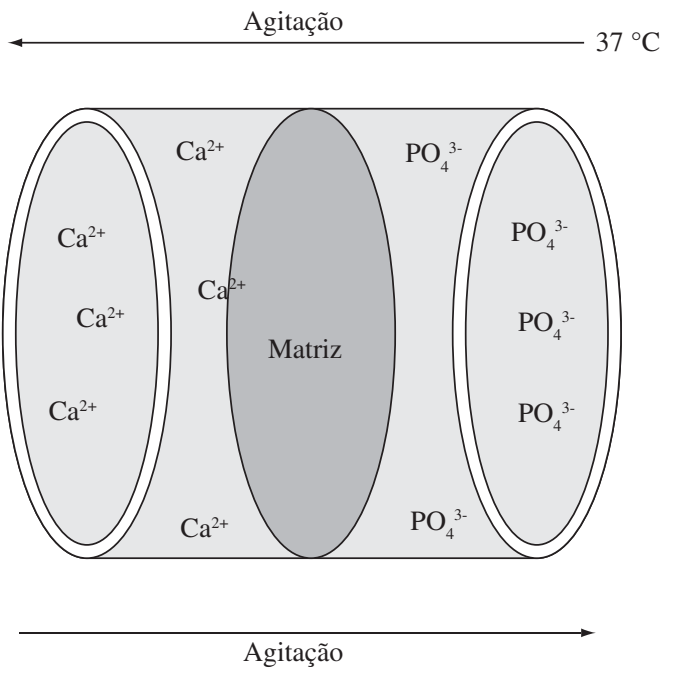

Figura 1. Esquema da cela dupla utilizada para calcificação das matrizes.
Zeiss-Jena Mod. URD-6, com potência de $40 \mathrm{kV}$, 20 mA e radiação de $\mathrm{CuK} \alpha 1,5406 \AA$;

S \%SPBCIROSCOPIA N INARAVEMEHO / ESPBCIR DE ABsorção na região do infravermelho foi obtido do pó superficial da matriz calcificada, em pastilhas de $\mathrm{KBr}$ em um intervalo entre 400 a $4000 \mathrm{~cm}^{-1}$, com resolução de $4 \mathrm{~cm}^{-1}$ utilizando um espectrofotômetro de FTIR BOMEN MB-120;

S \# AORMEIRA EXPICRAT RA DIHRNAA \$3\# \# URVA DSC foram obtidas em um equipamento TA Instruments, modelo DSC 2010 calibrado com padrão de índio. A razão de aquecimento foi de $10{ }^{\circ} \mathrm{Cmin}^{-1}$, na faixa de 20 a $180{ }^{\circ} \mathrm{C}$, em atmosfera de $\mathrm{N}_{2}$. Foram utilizadas massas de cerca de $10 \mathrm{mg}$, em suportes de alumínio herméticos. Os valores da temperatura de desnaturação (Td) foram obtidos pela inflexão da curva; e

s ! NÕISE THMOGRAMMÆTRCA 4' ! ! s ANÕISES FORAM realizadas com amostras de aproximadamente $10 \mathrm{mg}$, com variação de temperatura de 25 a $800{ }^{\circ} \mathrm{C}$ e razão de aquecimento de $10{ }^{\circ} \mathrm{Cmin}^{-1}$ sob fluxo de ar sintético, utilizando-se um equipamento TGA 2050 da TA Instruments.

\section{Resultados e Discussão}

As curvas DSC das amostras calcificadas em pH 7,4 (Figura 2a) mostraram um aumento na temperatura de desnaturação (Td) do colágeno em relação à amostra não calcificada. A matriz submetida a hidrólise alcalina (matriz A), apresenta transição em torno de $43{ }^{\circ} \mathrm{C}$. Os valores de Td para as maTRZE " \# \$ 上 \% FORAM pectivamente. Portanto, houve um aumento da Td devido ao processo de calcificação, indicando que a deposição de sais aumenta a estabilidade da hélice tripla. Esse mesmo efeito foi observado por Kronick et al. ${ }^{[1]}$ quando do estudo de desmineralização de matrizes ósseas.

As curvas termogravimétricas das matrizes A, B, C, D e E são mostradas na Figura 3. Essas curvas mostram 3 estágios que estão descritos na Tabela 1 . O primeiro de 25 a $150{ }^{\circ} \mathrm{C}$ pode ser atribuído à saída de água presente na matriz. O segundo estágio correspondendo ao início da decomposição do colágeno que ocorre em torno de $150-450{ }^{\circ} \mathrm{C}$. Entre 450-650 ${ }^{\circ} \mathrm{C}$ ocorre a carbonização da parte orgânica. Para as

Tabela 1. Porcentagens de perda de massa das matrizes derivadas de pele porcina obtidas através de TG.

\begin{tabular}{ccccc}
\hline & \multicolumn{3}{c}{ Perda de massa (\%) } & \\
\cline { 2 - 4 } Matriz & $\mathbf{2 5 - 2 5 0}{ }^{\circ} \mathbf{C}$ & $\mathbf{2 5 0 - 4 5 0}{ }^{\circ} \mathbf{C}$ & $\mathbf{4 5 0 - 6 5 0}{ }^{\circ} \mathbf{C}$ & $\begin{array}{c}\text { Resíduo } \\
\text { inorgânico } \\
(\%)\end{array}$ \\
\hline A & 12,6 & 53,6 & 33,2 & 0,6 \\
B & 9,3 & 37,2 & 23,6 & 29,9 \\
C & 9,6 & 36,8 & 22,3 & 31,2 \\
D & 13,1 & 37,3 & 27,1 & 21,8 \\
E & 12,5 & 37,3 & 26,0 & 23,8 \\
\hline
\end{tabular}




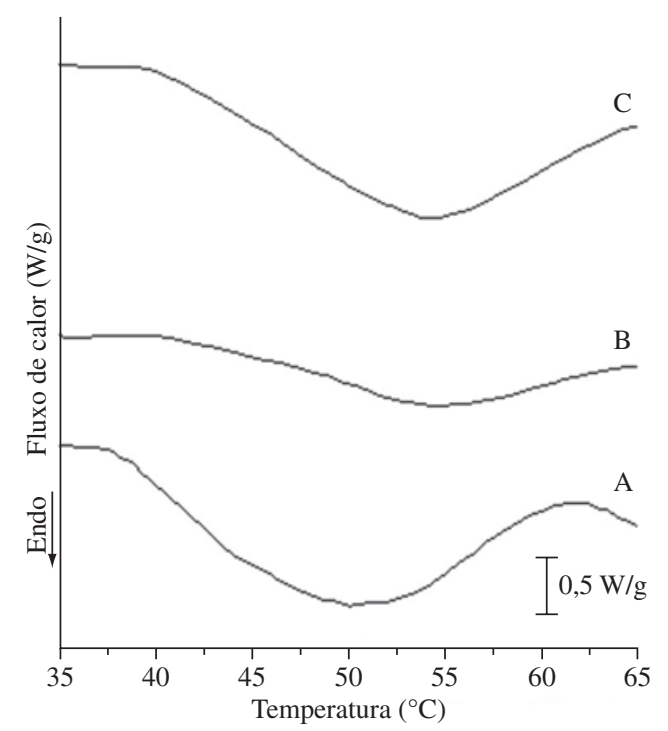

(a)

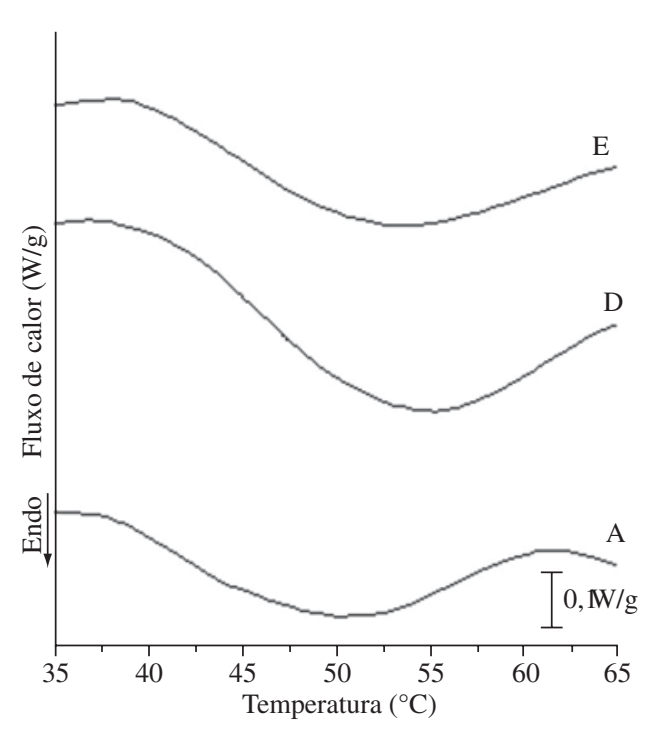

(b)

Figura 2. Curvas DSC das matrizes sem calcificação(A) e calcificadas por 24 (B e D) e 72h (C e E) em a) pH 7,4; e b) pH 9,0.

amostras calcificadas em pH 7,4 (Figura 3a) foi observando a maior porcentagem de resíduo inorgânico (obtido em $750{ }^{\circ} \mathrm{C}$ ), ao redor de $30 \%$. No caso das matrizes calcificadas em $\mathrm{pH} 9,0$ (Fig.3b) a porcentagem de resíduo foi em média de 22\%. Para a matriz sem calcificação há uma pequena quantidade $(0,6 \%)$ de resíduo inorgânico. Os diferentes tempos de calcificação induziram a valores diferenciados no resíduo inorgânico.

O espectro de absorção na região do infravermelho da pele porcina calcificada (Figura 4) mostrou bandas referentes ao colágeno entre 1200 e $2000 \mathrm{~cm}^{-1}$. Observou-se ainda uma forte banda em $3300 \mathrm{~cm}^{-1}$ que corresponde a superposição das bandas de deformação axial de $-\mathrm{OH}^{-} \mathrm{e}-\mathrm{NH}_{3}^{+}$. O espectro mostrou ainda bandas próximas a 500 e $1040 \mathrm{~cm}^{-1}$ correspondentes a íons fosfato. A banda larga na região de $3500-3400 \mathrm{~cm}^{-1}$ é

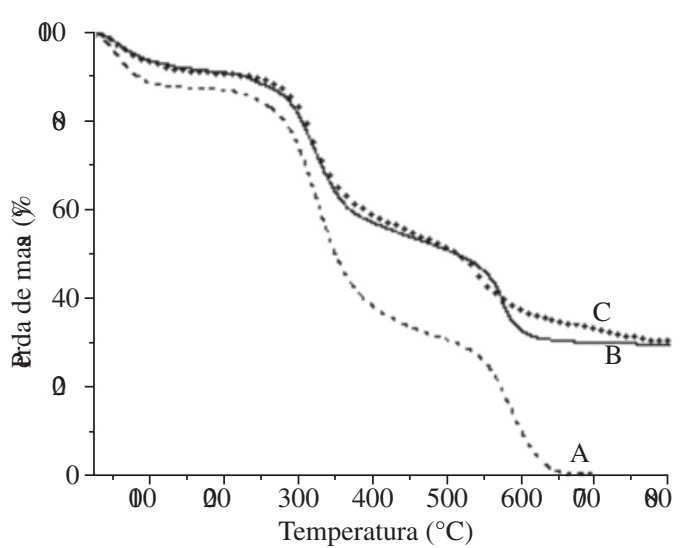

(a)

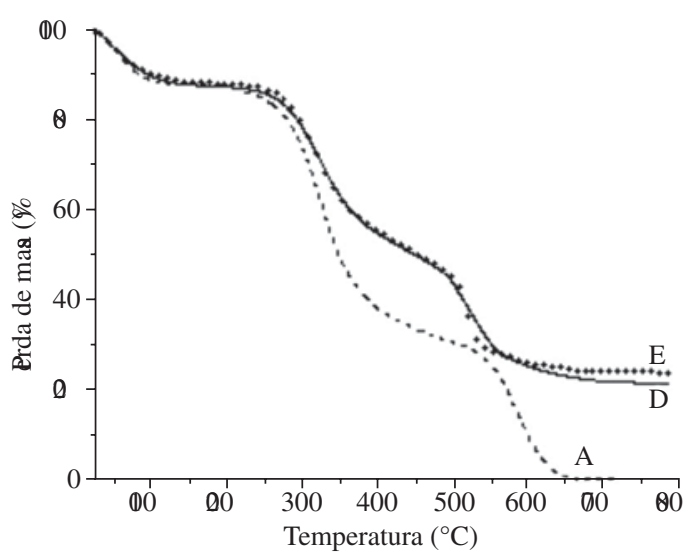

(b)

Figura 3. Curvas termogravimétricas das amostras não calcificada (A) e calGl CADASPOR "E\$ E H \# E\% EM A P( EB P(

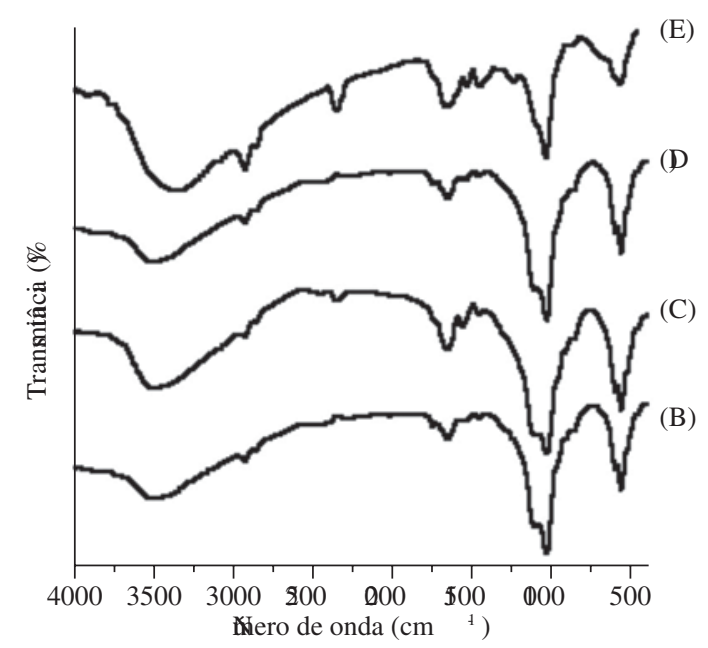

Figura 4. Espectro no infravermelho da pele porcina calcificada a $\mathrm{pH} 7,4$ (B) e (C) e pH 9,0 (D) e (E).

atribuída aos íons - $\mathrm{OH}^{-}$estrutural. O espectro obtido concorda com aqueles para HA/colágeno observados na literatura ${ }^{[12]}$.

A Figura 5 mostra o difratograma de raios $\mathrm{X}$ da matriz de pele porcina calcificada a $\mathrm{pH} 7,4$ (matriz $\mathrm{C}$ ), a mais calci- 


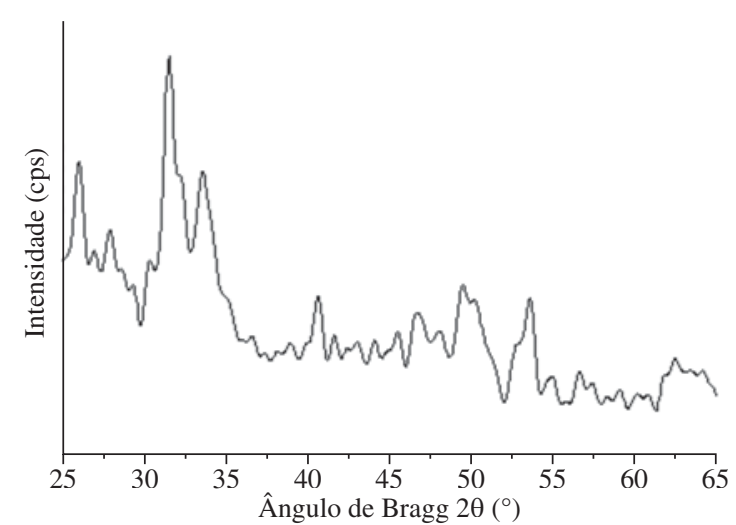

Figura 5. Espectro de difração de raios $X$ da pele porcina calcificada a pH 7,4 (matriz C).

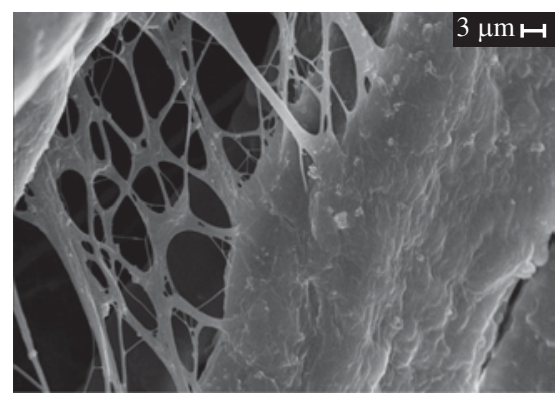

(a)

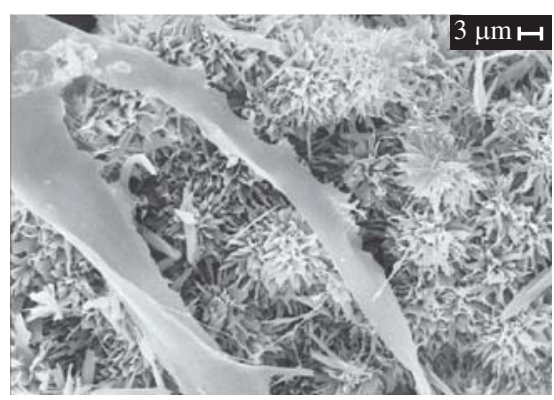

(b)

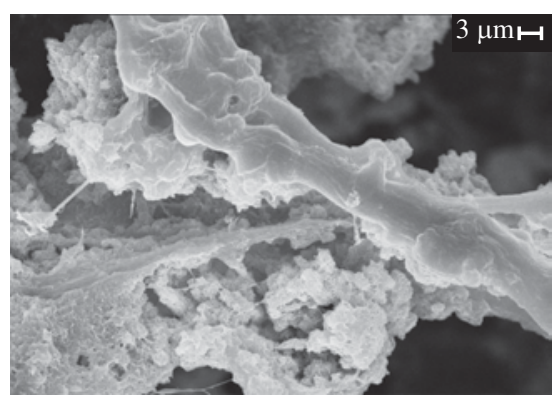

(c)

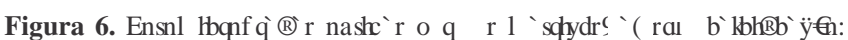
b) calcificadas por $72 \mathrm{~h} \mathrm{em} \mathrm{pH} \mathrm{7,4;} \mathrm{e} \mathrm{c)} \mathrm{pH} \mathrm{9,0.} \mathrm{Aumento} \mathrm{de} \mathrm{5000x.}$

ficada. Os sais de fosfato de cálcio formados na pele porcina mostraram o mesmo padrão em relação a HA, de acordo com o difratograma padrão da JCPDS (9-0432), com os picos principais observados para valores de d 2,83, 2,78, 2,67 e 3,43 $\AA$, contudo observa-se uma linha de base de maior in- tensidade para valores de d menores que 3,0 , sugerindo a presença de outros sais ${ }^{[13,14]}$.

Uma avaliação macroscópica das matrizes mostrou que após a calcificação estas se tornam mais rígidas e com a presença de sais brancos em sua superfície.

A Figura 6a mostra a fotomicrografia da matriz de pele porcina tratada sem calcificação, na qual pode-se observar as fibras de colágeno que a constituem. As Figura 6b e c mostram as matrizes calcificadas em ambos os pHs $(7,4$ e 9,0), observando-se a formação de sais sobre a matriz em ambos os casos. Os cristais formados entre as fibras das matrizes APIESENIARAM DUAS FORMAS DISIINIAS EVI AGUHAS \&GGRA B t aglomerados esféricos (Figura 6c). As matrizes calcificadas, principalmente para o $\mathrm{pH} 7,4$, apresentam uma morfologia similar àquela observada para a formação de HA em matrizes de colágeno ${ }^{[15]}$ e também de fosfato octacálcico ${ }^{[16]}$, que é o sal precursor na obtenção de HA.

\section{Conclusão}

$\mathrm{O}$ processo de calcificação, independentemente do $\mathrm{pH}$, forneceu matrizes mais estáveis termicamente como mostrado pelo aumento nos valores de Td. Esse processo dá origem a HA amorfa, obtendo-se a pH 7,4 uma maior formação do sal em relação ao $\mathrm{pH} 9,0$. A calcificação in vitro da pele porcina mostrou um resultado promissor quanto ao desenvolvimento de novos materiais para regeneração de tecido duro.

\section{Agradecimentos}

À CAPES pela bolsa concedida à T. M. Batista.

\section{Referências Bibliográficas}

1. Wahl, D. A. \& Czernuszka, J. T. - Eur. Cell. Mater., 11, p.43-56 (2006).

2. Roveri, N.; Falini, G. \& Sidoti, M. C.; Tampieri, A.; Landi, E.; Sandri, M.; Parma, B. - Biomaterials, 23, p.441446 (2003).

3. Kikuchi, M.; Itoh, S.; Shizuko I.; Shinomiya K. \& Tanaka, J. - Biomaterials, 22, p. 1705-1711 (2001).

4. Valente, M.; Ius, P.; Bortolotti, U.; Talenti, E.; Bottio, T. \& Thiene, G. - J. Heart Valve Dis., 7, p.180-189 (1998).

5. Burg, K. J. L.; Porter, S. \& Kellam, J. F. - Biomaterials, 21, p.2347-2359 (2000).

6. Yaylaoglu, M. B.; Yildiz, C.; Korkusuz, F. \& Hasirci, V. Biomaterials, 20, p.1513-1520 (1999).

7. Du, C.; Cui, F. Z.; Zhu, X. D. \& de Groot, K. - J. Biomed. Mater. Res, 44, p.407-415 (1999).

8. Lacerda, C.; Plepis, A. M. G. \& Goissis, G. - Química Nova, 21, p.267-271 (1998). 
9. Martins, V. C.A.; Goissis, G.; Ribeiro, A. C.; Marcantônio Jr, E. \& Bet, M. R. - Artif. Organs, 22, p.215-221 (1998).

10. Ruszczak, Z. - Adv. Drug Deliv. Rev., 55, p.1595-611 (2003).

11. Kronick, P. L. \& Cooke, P. - Connect. Tissue Res.; 33, p.275-82 (1996)

12. Chang, M. C. \& Tanaka, J. - Biomaterials, 23, p.48114818 (2002).

13. Carrodeguas, R. G.; Alonso, L. M.; García-Menocal, J. A. D.; Alonso, L. M.; Molins, M. P. G.; Manent, S. M.;
Mur, J. G.; Pérez, J. T. \& Estany, J. A. P. - Materials Research, 6, p.395-401 (2003).

14. Bian, J. J.; Kim, D. W. \& Hong, K. S. - J. Eur. Ceram. Soc., 23, p.2589-2592, (2003).

15. Lickorish, D.; Ramshaw, J. A. M.; Werkmeister, J. A.; Glattauer, V. \& Howlett, R. - J. Biomed. Mater. Res., Part A, 68, p.19-27 (2004).

16. Honda, Y.; Kamakura, S.; Sasaki, K. \& Suzuki, O. J. Biomed. Mater. Res., Part B, 80, p. 281-289 (2006).

Enviado: 03/01/07 Reenviado:03/04/07 Aceito:01/06/07 